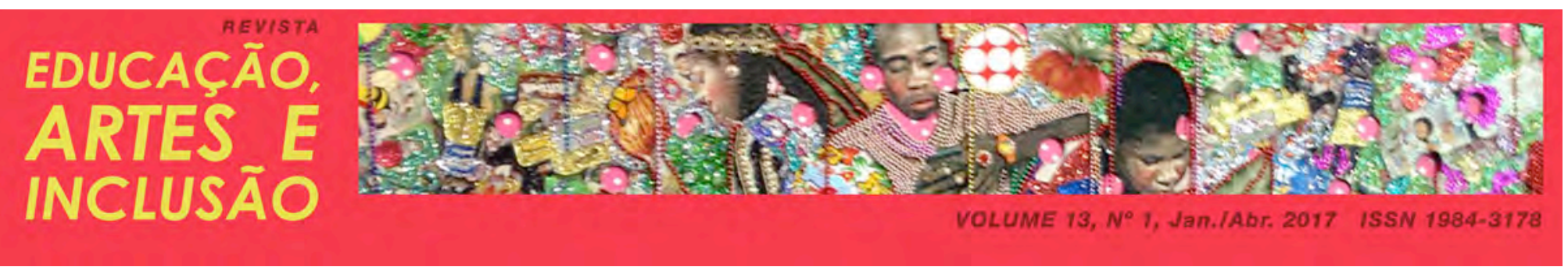

\title{
A INCLUSÃO DO ALUNO COM DEFICIÊNCIA VISUAL EM CONTEXTO ESCOLAR: AFETO E PRÁTICAS PEDAGÓGICAS
}

\author{
THE INCLUSION OF STUDENT WITH VISUAL DEFICIENCY IN \\ SCHOOL CONTEXT: AFFECTION AND PEDAGOGICAL PRACTICES
}

DOI: $\underline{\text { http://dx.doi.org/10.5965/1984317813012017008 }}$

Larissa Oliveira Mesquita Ribeiro - FIBRA

\begin{abstract}
RESUMO
$\mathrm{O}$ artigo tem como objetivo compreender a função da afetividade e das práticas pedagógicas no processo de inclusão do aluno com deficiência visual. A partir de levantamentos bibliográficos, constatou-se que a inclusão escolar tem sido muito discutida nos últimos anos, inclusive em relação ao acesso dos alunos com deficiência visual em classes regulares de ensino. Está estabelecido em legislação que é dever do Estado garantir uma educação de qualidade a todos os alunos. Verificou-se ainda que a efetivação do processo de inclusão escolar depende de vários outros aspectos, entre os quais dois ganham especial destaque, a afetividade, que precisa ser um elemento marcante na relação entre a diversidade de sujeitos na escola, mas fundamentalmente entre professores e alunos; e também as práticas pedagógicas, que são de suma importância para o processo de ensino-aprendizagem e desenvolvimento do aluno com deficiência visual.
\end{abstract}

Palavras-chave: Inclusão. Deficiência Visual. Afetividade. Práticas Pedagógicas.

\begin{abstract}
The article has such as general objective to understand the affectivity about pedagogical practice into the inclusion process of visual deficient student. Through bibliographic survey, established that school inclusion has been much discussed at the last few years, there is also about relationship between the accesses from visual deficient students into the regular classes. It had been established in lawmaking that is a duty from government to guarantee a quality education to all students. Observed that even though the carrying out of school inclusion process depends on several others aspects, between that two of them get more prominence, the affectivity, which need to be an outstanding element at relation among several subjects into school, but fundamentally between teachers and students; and also pedagogical practice, which are extremely important to the process of teaching-learning and about develop of visual deficient student.
\end{abstract}

Keywords: Inclusion. Visual Deficiency. Affectivity. Pedagogical Practice. 


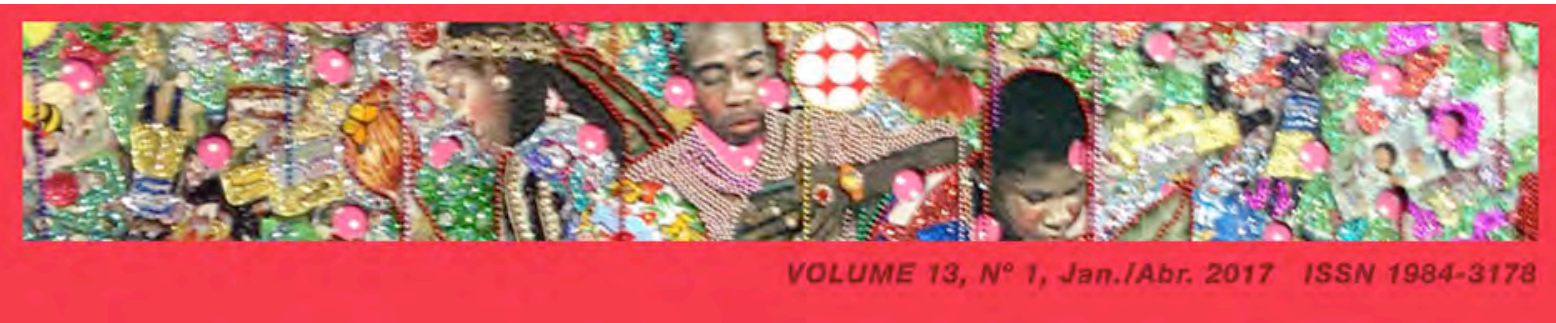

\section{INTRODUÇÃO}

A inclusão de alunos com deficiência visual (DV) no sistema regular de ensino vem aumentando a cada ano, ampliando, assim, a necessidade da escola de estar preparada para receber esses alunos de forma inclusiva, acolhedora e afetuosa. Segundo INEP/MEC (2016), o número de matrículas na educação especial no âmbito da educação básica passou de 325.136, em 2007, para 750.983, em 2015. Com isso, ainda de acordo com INEP/MEC, 56,6\% das escolas brasileiras possuíam em 2015 alunos com deficiências incluídos em turmas regulares, enquanto em 2008 eram apenas $31 \%$ das escolas.

Com a promulgação da Constituição da República Federativa do Brasil (1988), e com a regulamentação da Lei de Diretrizes e Bases da Educação Nacional/LDB, Lei nº 9.394, de 20 de dezembro de 1996. As pessoas com deficiência passam a ter pleno direito de acesso e permanência no âmbito escolar, devendo ser proporcionada uma educação digna a todos os educandos.

Nesse sentido, a inclusão nas escolas ganhou grandes contribuições com a Constituição Federal (1988) que caracteriza, em seu Artigo 205, a inclusão como princípio de direito das pessoas com deficiência no âmbito social e escolar:

A educação, direito de todos e dever do Estado e da família, será promovida e incentivada com a colaboração da sociedade. Visando o pleno desenvolvimento da pessoa, seu preparo para o exercício da cidadania e sua qualificação para o trabalho (BRASIL, 2013, p. 34).

Diante dessa perspectiva de inclusão, a escola deve garantir a permanência e o acesso do aluno com DV nas classes regulares de ensino da mesma forma que assegura aos demais. Com os mesmos direitos e deveres e valorizando, acima de tudo, as diferenças de cada educando.

O trabalho pedagógico com as crianças no contexto escolar precisa ganhar uma dimensão mais ampla, passando a atender às especificidades de cada aluno e seu desenvolvimento. Nesse sentido, a função da afetividade passa a ser de suma importância para construção de um ambiente propício a aprendizagem, onde a criança se sinta amada e respeitada, independente da sua deficiência. 
Rodrigues (2008, p. 18) argumenta que no pensamento de Wallon "a afetividade diz respeito a um conceito amplo, uma situação mais permanente, que engloba em seu interior os sentimentos, as emoções e as paixões e manifesta estados de sensibilidade [...]”. Assim, a relação afetiva contribui para o desenvolvimento cognitivo do aluno, porém essa relação necessita ocorrer desde o primeiro momento em que o aluno ingressa na escola por meio da direção, dos professores, dos funcionários, dos alunos e da comunidade em geral.

A afetividade na escola precisa ser a mediação para o processo de ensinoaprendizagem do aluno, contribuindo para a sua cidadania. Sendo assim, o que se busca são práticas pedagógicas inovadoras em prol de um aluno sujeito do processo de ensinoaprendizagem e no âmbito do qual o professor passe a levar em conta que cada criança tem uma forma específica de se desenvolver.

Essa discussão motivou a base da seguinte problemática: Qual a função da afetividade e das práticas pedagógicas no processo de inclusão do aluno com deficiência visual? Por sua vez, visando um melhor detalhamento dessa problemática foram estabelecidas as seguintes questões norteadoras: De que forma ocorre o processo de inclusão de alunos com deficiência visual no contexto escolar? Qual o significado do afeto no processo de inclusão do aluno com deficiência visual em contexto escolar? Como as práticas pedagógicas atuam no processo ensino-aprendizagem do aluno com deficiência visual?

O interesse pelo estudo sobre alunos com DV no contexto escolar surgiu durante a realização de um curso de Braille e também de curso de orientação e mobilidade para alunos com DV. Percebe-se que a afetividade e as práticas pedagógicas para os alunos com DV no contexto escolar ainda precisam ser estimuladas e melhor trabalhadas.

Diante os aspectos supracitados, foram observados inúmeros desafios que a criança com DV tem que enfrentar durante a sua trajetória escolar, pois alguns educadores precisam desenvolver um trabalho mais afetuoso e inovador. Conforme aponta Brasil (2012), é possível identificar iniciativas das escolas das redes regulares de ensino para o atendimento do aluno com DV, porém, para que haja a inclusão é necessário que os professores se sensibilizem e inovem suas práticas, propiciando novas formas para que os alunos recebam os conhecimentos. 
Brasil (2012) ressaltar que as condições físicas das escolas, como mobiliário e infraestrutura, precisam ser implantadas, buscando facilitar a mobilidade e a autonomia do aluno com DV dentro do ambiente escolar. Pois nota-se que o desenvolvimento educacional dos alunos com DV ainda é muito dificultado, mesmo diante de tantos avanços na sociedade atual, ou seja, muitas barreiras precisam ser rompidas para que se possa realmente alcançar a verdadeira inclusão para esses alunos. Nesse sentido, o trabalho possui relevância por pensar alguns desses fatores que implicam na inclusão escolar de alunos com DV, como o afeto e as práticas pedagógicas.

A presente pesquisa objetiva, de forma geral, compreender a função da afetividade e das práticas pedagógicas no processo de inclusão do aluno com DV. E de forma mais específica, objetiva caracterizar o processo de inclusão de alunos deficientes visuais no contexto escolar; analisar o significado do afeto no processo de inclusão do deficiente visual na escola; e entender a atuação das práticas pedagógicas no processo ensino-aprendizagem e inclusão do aluno com deficiência visual.

O estudo está pautado numa análise dialética da problemática já exposta, entendendo a educação a partir de uma concepção dialética, como defendido por Gadotti (2001), que considera que o desenvolvimento humano é estabelecido mediante determinantes internos e externos. A questão central numa abordagem dialética da educação é "[...] o homem enquanto ser político, a libertação histórica, concreta do homem contemporâneo [...]” (p. 158).

A metodologia empregada na busca das respostas às indagações expostas anteriormente possui um caráter qualitativo e pretende contribuir para que se possa compreender sobre o assunto estudado, que envolve a deficiência visual, a inclusão, o papel da afetividade no contexto escolar e as práticas pedagógicas.

A base metodológica fundamental se estabelece a partir do levantamento bibliográfico a respeito da afetividade, da inclusão e das práticas pedagógicas voltadas aos alunos com DV, como será detalhado posteriormente.

O artigo está organizado da seguinte forma: inicialmente é apresentada e discutida a fundamentação teórica do trabalho, que possui três subdivisões, uma primeira seção discute a inclusão escolar do aluno com DV; uma segunda trata da afetividade no contexto escolar; e 
uma terceira seção discorre sobre as práticas pedagógicas e seu significado para a aprendizagem e para inclusão do aluno com DV.

Após a fundamentação teórica têm-se os esclarecimentos a respeito da metodologia utilizada no desenvolvimento da pesquisa e, em seguida, são apresentados os resultados e as discussões do material levantado e organizado. Por fim, são expostas as conclusões do estudo.

\section{ESCOLA, DEFICIÊNCIA VISUAL E INCLUSÃO}

Como enfatiza Demo (2009), a escola como um todo é o lugar da aula. Porém é necessário mudar essa concepção tradicionalista. Segundo o autor, uma ideia bastante interessante é tornar a escola um "laboratório de aprendizagem", um lugar de pesquisa e de conhecimento. Poderia ser acrescentada às considerações do autor a constatação de que a escola também deve ser um espaço da inclusão, pois a realização de suas funções envolve alunos, diretores, pessoal de apoio e toda a comunidade escolar.

De acordo com Libâneo (2010), os processos de transformações sociais afetam diretamente o sistema educacional e consequentemente a aprendizagem do aluno. Para o autor, "[...] a escola, precisa reciclar-se para assumir seu papel nesse contexto como agente de mudanças, geradora de conhecimento, formadora de sujeitos capacitados a intervir e atuar na sociedade de forma crítica e criativa" (p. 195).

Diante desse contexto, torna-se indispensável a construção de uma escola inclusiva, estando aberta para receber alunos com deficiência e estabelecendo relações significativas para o futuro dos educandos, tornando-os cidadãos capazes de lidar com os desafios e dificuldades impostas pela sociedade contemporânea.

O Decreto $\mathrm{n}^{\mathrm{0}} 5.296$, de 2 de dezembro de 2004, considera a deficiência visual como:

[...] cegueira, na qual a acuidade visual é igual ou menor que 0,05 no melhor olho, com a melhor correção óptica; a baixa visão, que significa acuidade visual entre 0,3 e 0,05 no melhor olho, com a melhor correção óptica; os casos nos quais a somatória da medida do campo visual em ambos os olhos for igual ou menor que $60^{\circ}$; ou a ocorrência simultânea de quaisquer das condições anteriores (BRASIL, 2004, p. 14). 


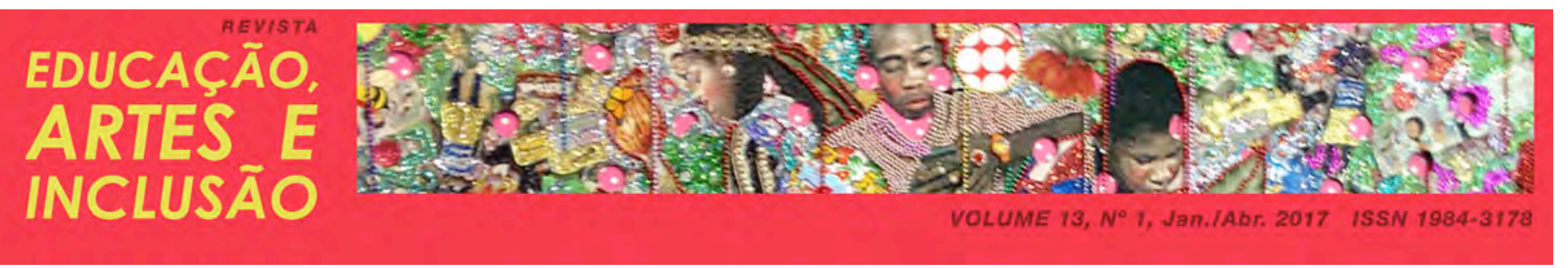

A deficiência visual está dividida entre a cegueira e a baixa visão, que pode ser congênita ou adquirida. As causas de origem congênita podem ser diversas, tais como retinite pigmentosa, glaucoma e catarata congênita. Dentre essas causas, alguns fatores são mais frequentes como a desnutrição gestacional, toxoplasmose, rubéola, dentre outros. A DV também pode ser adquirida através de acidentes ou doenças como: deslocamento da retina, catarata, traumas oculares e outros (BRASIL, 2001a).

Brasil (2001a) define baixa visão como uma alteração da capacidade funcional da visão, isso leva a vários fatores:

[...] baixa acuidade visual significativa, redução importante do campo visual, alterações corticais e/ou de sensibilidade aos contrastes que interferem ou limitam o desempenho visual do indivíduo. A perda da função visual pode ser em nível severo, moderado ou leve, podendo ser influenciada também por fatores ambientais inadequados (BRASIL, 2001a, p. 33).

Já a cegueira é a perda total da visão até a ausência de projeção de luz, ou seja, envolve as pessoas que possuem redução da acuidade visual central. Brasil (2001a) define a deficiência visual abarcando pessoas com baixa visão e pessoas cegas.

As pessoas com baixa visão apresentam "desde condições de indicar projeção de luz até o grau em que a redução da acuidade visual interfere ou limita seu desempenho" (BRASIL, 2001a, p. 34). Nesse sentido, o processo educacional do aluno com baixa visão se desenvolverá por meio de diversos recursos específicos a sua limitação, principalmente a partir de recursos visuais ampliados (BRASIL, 2001a).

As pessoas cegas apresentam "desde ausência total de visão até a perda da projeção de luz” (BRASIL, 2001a, p. 35). No caso das pessoas com cegueira total o processo de ensinoaprendizagem será por meio dos outros sentidos (tato, audição, olfato, paladar), e também utilizando o sistema Braille para a escrita (BRASIL, 2001a).

É importante que o professor esteja sempre atento, no caso de algum aluno apresentar sinais, posturas e sintomas referentes à DV e fazer o encaminhamento necessário ao especialista, pois quanto mais cedo for feito o diagnóstico, mais chances terá o aluno de um desenvolvimento com estimulações no seu ambiente escolar. 
No quadro 01 estão organizados alguns sinais e sintomas mais comuns de alterações visuais, destacados por Brasil (2001a), e que requerem atenção do professor. Diante desses sinais, torna-se muito importante a observação do professor no momento das atividades e da própria conduta do aluno ao apresentar esses sintomas. Porém, vale ressaltar que essa avaliação precisa ser desenvolvida por um especialista da área por meio de um exame clínico, onde será diagnosticada a deficiência, podendo ser classificada como baixa visão ou cegueira.

Quadro 01: Sintomas e sinais mais comuns de alterações visuais

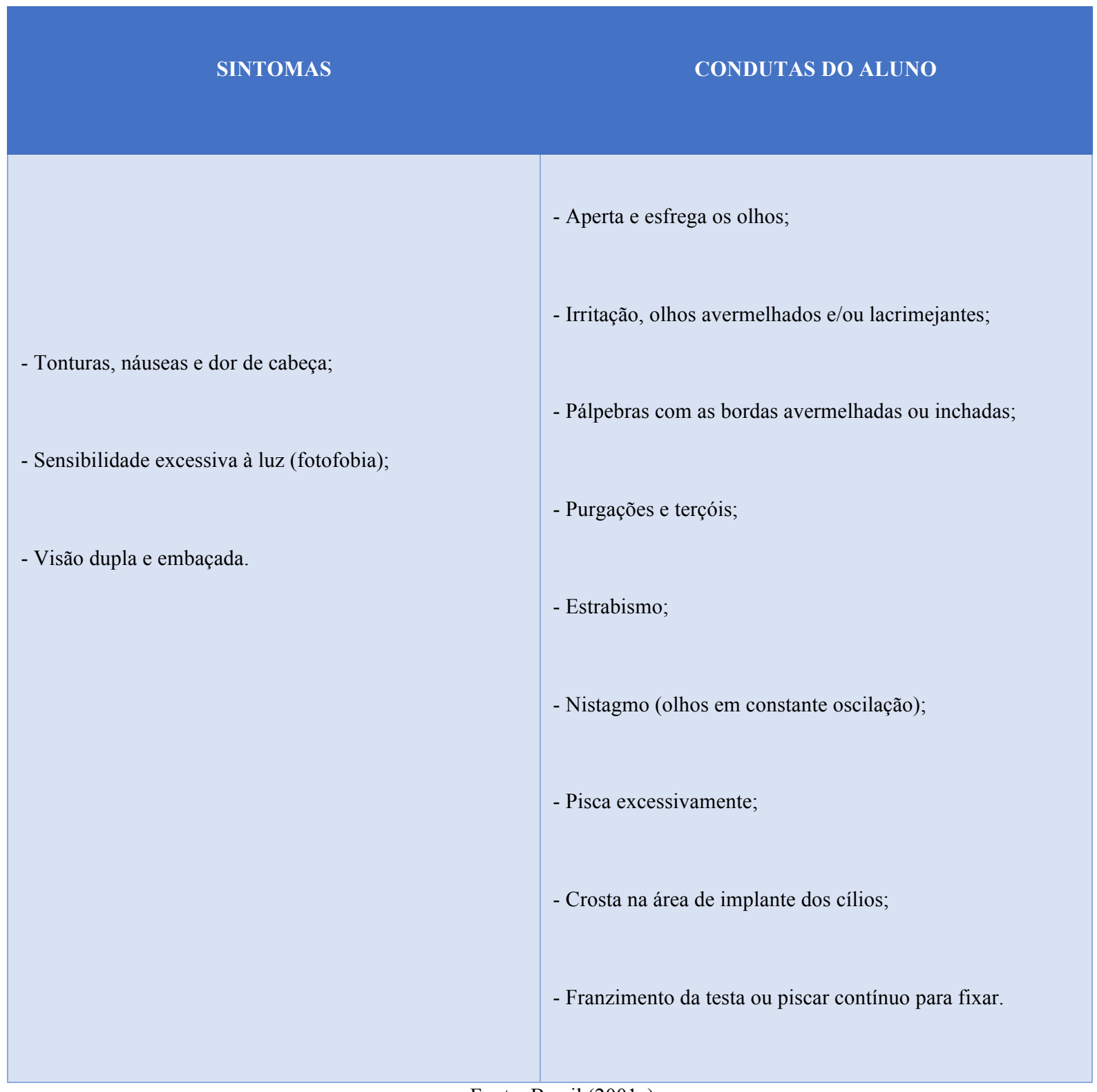

Fonte: Brasil (2001a). 
Os alunos com DV, devem estar inclusos no sistema regular de ensino, atendendo aos princípios da educação inclusiva, e de uma escola para todos. Para Brasil (2001b, p. 98), a inclusão do aluno com DV nas classes comuns de ensino "deve ser um processo preferencial, com possibilidade de progresso, êxito e condições de desenvolvimento da aprendizagem".

De acordo com Brasil (2012), a inclusão do aluno com DV no âmbito escolar demanda uma organização com várias propostas de trabalho e especificidades à pessoa humana, pois a inclusão escolar ainda enfrenta muitas barreiras para que possa atingir a educação como direito de todos.

Essas barreiras vêm desde a não aceitação de alunos com DV nas classes comuns, já que muitas escolas rejeitam os alunos com DV, não cumprindo a Constituição Federal de 1988, conforme estabelece no Art. 208: “dever do Estado com a educação será efetivado mediante a garantia de: III - atendimento educacional especializado aos portadores de deficiência, preferencialmente na rede regular de ensino".

Essa realidade precisa ser rompida, fazendo com que os alunos tenham direito de uma educação inclusiva que possibilite novos horizontes para o seu desenvolvimento. Segundo Brasil (200 a, p. 171), “a inclusão não é simplesmente aproximação física, estar junto, mas a possibilidade de comunicação-ação-participação". Ou seja, garantir que o aluno interaja com o meio, brincando, conhecendo outras crianças, compartilhando outras vivências.

De acordo com Bruno (2006, p. 14), “a inclusão é um processo complexo que configura diferentes dimensões: ideológica, sociocultural, política e econômica". Diante desses aspectos, a inclusão escolar necessita apresentar como ponto primordial uma educação voltada para o coletivo, todos trabalhando juntos em busca de uma educação para todos, fazendo com que seja criado um laço de afetividade no âmbito escolar.

Com a afetividade no ambiente escolar o aluno com DV passa a se sentir amado, valorizado e respeitado. O afeto, como elemento caracterizador das relações entre os vários sujeitos do ambiente escolar, precisa ser discutido com atenção, pois interfere de forma relevante tanto no processo de inclusão quanto na aprendizagem. 


\section{AFETO E INCLUSÃO EM CONTEXTO ESCOLAR}

O aprofundamento do processo inclusivo na escola, seja em relação ao aluno com DV ou a qualquer outro, pressupõe mudanças que vão desde a adaptação da estrutura física da escola até a modificação de posturas e mentalidades dos agentes que compõem o contexto escolar. Desse modo, cabe ressaltar a importância da afetividade no ambiente escolar e também no desenvolvimento dos alunos.

A palavra afeto, segundo Ferreira (2001, p. 20) significa "afeição, amizade, amor e objeto de feição". Boato (2009) e Carmo (2011) destacam como aspecto central na teoria de Wallon as emoções no desenvolvimento do indivíduo e na relação com o meio. Wallon (1995) considera a afetividade elemento indispensável no desenvolvimento do indivíduo, já que é por seu intermédio que a pessoa expressa seus desejos e vontades.

A emoção seria a base do desenvolvimento da inteligência, já que é o meio de comunicação inicial da criança, através da qual ela irá comunicar suas necessidades e desejos e, portanto, estabelecer sua relação com os outros indivíduos. Mas não se restringe à criança, acompanha o ser humano em toda a sua vida.

O contexto escolar também é permeado pelas emoções enquanto "exteriorização da afetividade", nas palavras de Wallon (1995, p. 152). A própria prática do professor, na busca de constituição da aprendizagem por parte dos educandos, é mediada pela afetividade. Como destacam Codo e Gazzotti (1999), todo trabalho pressupõe algum nível de afetividade, porém o caso do professor seria diferente, para que seu trabalho se realize a relação afetiva necessita se estabelecer. Como ressaltam os autores:

Através de um contato tácito, onde o professor se propõe a ensinar e os alunos se dispõem a aprender, uma corrente de elos de afetividade vai se formando, propiciando uma troca entre os dois. Motivação, cooperação, boa vontade, cumprimento das obrigações deixam de ser tarefas árduas para os alunos. Interesse, criatividade, disposição para exaustivamente sanar dúvidas, estimulam o professor. Em outras palavras, o papel do professor acaba estabelecendo um jogo de sedução, onde ele vai conquistar a atenção e despertar o interesse do aluno para o conhecimento que ele está querendo abordar. (CODO e GAZZOTTI, 1999, p. 50). 
Dessa forma, o processo de ensino-aprendizagem pressupõe relações afetivas. Andersen (2011, p. 12) afirma que o "ser humano é primordialmente emocional e precisa ser entusiasmado a aprender. Não é uma simples máquina a ser programada. E esse entusiasmo precisa ser resultado de uma relação afetiva e determinada". Em outros termos, a relação afetiva contribui para o desenvolvimento do aluno, porém essa relação deve ocorrer a partir do primeiro contato do aluno com a escola e com o seu professor.

$\mathrm{O}$ aluno com DV, como qualquer outro ser humano, necessita de boas relações para que possa se sentir amado, querido, respeitado e, acima de tudo, valorizado. Desse modo, as relações afetivas no ambiente escolar contribuem para o crescimento e desenvolvimento desse aluno, que, assim, tem maiores chances de apresentar bons resultados no seu aprendizado escolar.

Para Almeida (2008, p. 34) a afetividade consiste numa terminologia usada para “identificar um domínio funcional abrangente e, nesse domínio funcional, aparecem diferentes manifestações; desde as primeiras, basicamente orgânicas, até as diferenciadas, como as emoções, os sentimentos e as paixões".

A afetividade cria laços de amor, amizade e deve ser um elemento marcante na relação professor-aluno e também nas relações com todo o corpo docente da escola. A escola precisa construir uma relação afetiva com os alunos e, principalmente, o professor, que está diretamente em contato com os mesmos no cotidiano, precisa fazer do espaço da sala de aula um lugar favorável a mudanças, a questionamentos e à inclusão.

É importante levar em consideração que em uma sala de aula os alunos precisam de relações afetivas para que possam se desenvolver e, dessa maneira, lidar com as diferenças de cada indivíduo que nela se encontra. Mahoney (2004, p. 17), utilizando-se das reflexões de Wallon, considera a afetividade como responsável

[...] pelas emoções, pelos sentimentos e pela paixão, que são sinalizadores de como o ser humano é afetado pelo mundo interno e externo. Essa condição de ser afetado pelo mundo estimula tanto os movimentos do corpo como a atividade mental. São recursos de sociabilidade, de comunicação, exercendo atração sobre o outro com o apoio do ato motor. 
Assim, a afetividade está diretamente ligada às emoções sentidas pelo ser humano, emoções essas que fazem parte de seu cotidiano, do local em que está inserido. No caso da escola, a afetividade influencia todo o processo educacional do aluno e essa relação de afeto está baseada em saber incluir o outro independente de sua deficiência.

Para Andersen (2011, p. 12-13) "educar é uma tarefa sublime e não, ao contrário do que muitos dizem, uma tarefa apenas para quem nasceu para isso". Desse modo, a educação e a afetividade são inseparáveis, pois, educar não é simplesmente ensinar, mas sim criar laços afetivos no ambiente escolar. Em sala de aula o professor encontra realidades diversas, por esse motivo, a importância de conquistar o aluno e de demonstrar a atenção necessária a cada um deles.

O professor precisa deixar claro a sua presença em sala de aula e nunca deve esquecerse de nenhum dos seus alunos, para que eles não se sintam desprezados. Em uma sala de aula heterogênea cada aluno possui uma história de vida, e com isso observa-se uma série de fatores que podem influenciar em sem desenvolvimento escolar (ANDERSEN, 2011).

Fatores como a família, mais especificamente a falta de afeto dos pais com relação aos seus filhos, interferem diretamente em seu aprendizado. No caso do aluno com DV, a família deve estar presente na escola, garantindo que o aluno se desenvolva e esteja incluso no processo educacional. Com isso, o papel da afetividade se torna muito positivo para o aluno com DV.

Amorim (2012, p. 5) destaca que “[...] a família tem a função de preparar o emocional da criança, principalmente nos primeiros anos escolares, pois o meio familiar em que a criança está inserida é o seu primeiro ambiente de aprendizagem”. O autor deixa clara a importância da família para o processo de ensino-aprendizagem do aluno.

Freire (2000, p.144) afirma que "a mediação do adulto é a principal coluna que sustenta o processo de apropriação de experiência pela criança, pois é ele que organiza o ambiente onde ela vive, além de ser o responsável pela sua educação”. Dessa forma, a escola e a família devem trabalhar juntas em prol do aluno, tornando a afetividade um elemento imprescindível para a construção de uma educação melhor e tornando o aluno com DV sujeito de uma educação digna. 
Sadalla e Azzi (2004, p. 2) contribuem definindo a afetividade como "um conjunto de fenômenos [...] que são expressos sob a forma de emoções, sentimentos e paixões relacionadas a prazer/dor, satisfação/insatisfação, agrado/desagrado, alegria/tristeza". O direcionamento desses sentimentos tem fortes implicações sobre a pessoa, sendo fundamental ao seu desenvolvimento e à conformação de sua personalidade.

Considerando essa perspectiva no ambiente escolar e fundamentalmente na relação professor-aluno, constata-se que a ocorrência das relações afetivas contribui para a construção de pessoas mais humanas e felizes, sendo capazes de conviver com as diferenças e sabendo incluir o próximo.

\section{AS PRÁticas PEdAGógICAS E SEU SIGNIFICAdo PARA A APRENDIZAGEM E INCLUSÃO DO ALUNO COM DEFICIÊNCIA VISUAL}

Como já referido anteriormente, a relação professor-aluno deve ser de respeito e afeto. Porém para complementar essa boa relação é necessário que o professor leve para sala de aula práticas pedagógicas que contribuam nesse sentido, promovendo um distanciamento do tradicionalismo e aproximando os educandos do processo de elaboração das aulas, desenvolvendo, desde a escolha dos temas a serem abordados até a participação direta nas atividades.

Mantoan (2004, p. 06) afirma que a "Educação Especial, na perspectiva inclusiva, tem papel imprescindível e não pode ser negado, embora dentro dos limites de suas atribuições, sem extrapolar seus espaços de atuação específica”. Com isso, as escolas precisam se adaptar às necessidades especificadas de seus alunos, buscando não apenas a aceitação do aluno com DV nas classes regulares de ensino, mas sim fazer valer de fato a educação inclusiva, enfrentando desafios e buscando cada vez mais melhorias na qualidade do ensino.

Segundo Freire (2001, p. 47) "ensinar não é transferir conhecimento, mas criar as possibilidades para a sua própria produção ou a sua construção". Isso leva a vários questionamentos sobre as práticas adotadas pelos professores diante do aluno com deficiência visual, pois, na maioria dos casos, o aluno é taxado como "coitado" e "incapaz", simplesmente pelo fato de possuir uma deficiência. 
$\mathrm{Na}$ realidade, os alunos com DV devem ter acesso aos mesmos conteúdos que os demais alunos, o que vai diferenciar, na maioria das vezes, é a metodologia empregada pelo professor para que esse aluno consiga adquirir os conhecimentos necessários para a sua aprendizagem. Um primeiro ponto a se pensar sobre a prática docente é a mudança de postura, exigindo desse a consideração do aluno como um sujeito da aprendizagem, capaz de pensar, construir, discordar etc.

Segundo Minetto (2008, p. 19) “a educação é responsável pela socialização, que é a possibilidade de convívio, com qualidade de vida, de uma pessoa na sociedade; viabiliza, portanto, com um caráter cultural acentuado, a integração do indivíduo com o meio”. Ou seja, a escola conduz os indivíduos para a vida na sociedade, conhecendo novas culturas, fazendo com que o aluno quebre a barreira do preconceito e conheça a diversidade que existe em sua volta.

Para Santos (2006) o professor precisa superar procedimentos como "dar" aula, que pressupõe um papel passivo ao aluno; estabelecer respostas prontas e instruções em demasia, pois estas precisam ser construídas pelos alunos. E, por outro lado, precisa buscar inovações que desafiem os alunos, que tornem a aprendizagem interessante e prazerosa. Os estímulos e a interação entre os alunos também contribuem para a prática pedagógica do professor interessado na construção de uma aprendizagem significativa.

A inclusão nas escolas, mais especificamente em contexto de sala de aula, deve partir do professor, utilizando estratégias inovadoras para sua aula, fazendo com que todos os alunos tenham uma participação ativa. Diante desses fatores, Bruno (2006, p. 18) afirma que:

[...] a sala de aula inclusiva propõe um novo arranjo pedagógico: diferentes dinâmicas e estratégias de ensino para todos, e complementação, adaptação e suplementação curricular quando necessários. A escola, a sala de aula e as estratégias de ensino é que devem ser modificadas para que o aluno possa se desenvolver e aprender.

Essas são algumas das condições essenciais e importantes citadas por Bruno (2006) que devem ser prioridades nas escolas para o processo de inclusão dos alunos com deficiência. As práticas dos professores precisam estar diretamente ligadas a essas condições, 
fazendo assim novas ações que contribuam para o processo de aprendizagem dos alunos com deficiência visual. Ou seja, um trabalho em conjunto entre professor-aluno a fim de proporcionar aos alunos uma melhor aprendizagem.

Diante das práticas desenvolvidas pelos docentes, vale citar como instrumentos importantíssimos a utilização de recursos didáticos, que irão ajudar de forma significativa na aprendizagem dos alunos com DV. Esses recursos devem promover a interação e comunicação entre todos os alunos da classe fazendo com que haja um entrosamento.

Segundo Brasil (2001b, p. 75) os recursos didáticos são muito importantes para a educação dos alunos com DV, considerando-se que:

[...] um dos problemas básicos do aluno com deficiência visual, em especial o aluno cego, é a dificuldade de contato com o ambiente físico; a carência de material adequado pode conduzir a aprendizagem da criança deficiente visual a mero verbalismo, desvinculado da realidade [...].

Conforme Sá; Campos e Silva (2007), os recursos didáticos podem ser produzidos a partir de vários materiais de baixo custo e de materiais que podem ser reaproveitados, entre eles vale citar: embalagens descartáveis, frascos, tampas de vários tamanhos, retalhos de papéis e tecidos com texturas diferentes, botões, palitos, crachás, barbantes, sementes, dentre outros.

Os autores também destacam algumas sugestões de materiais que podem ser confeccionados para trabalhar com o aluno com DV. Entre eles estão: o Jogo da velha: que pode ser feito com papelão, isopor, madeira e com peças de encaixe; a Cela Braille: que pode ser confeccionada com caixas de papelão, frascos de desodorantes e embalagens de ovos; e muitos outros recursos (SÁ; CAMPOS; SILVA, 2007).

A figura 1 demonstra o jogo da velha, confeccionado com madeira e peças de encaixe, usado para trabalhar a dimensão de tamanhos com alunos com deficiências visuais. Já a figura 2 demonstra a Cela Braille, confeccionada a partir de materiais recicláveis. Esse tipo de jogo pode ser usado para facilitar o aprendizado da escrita Braille do aluno com DV. 


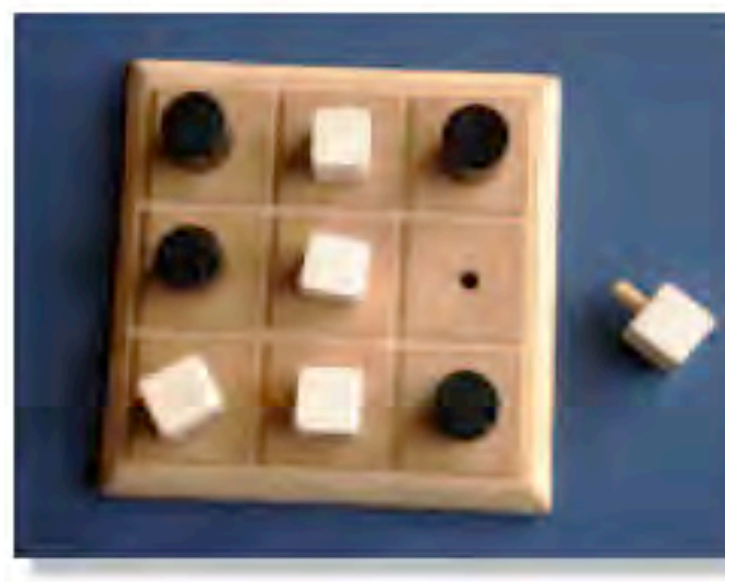

Figura 01: Jogo da velha (Recursos materiais)

Fonte: Sá; Campos e Silva (2007).

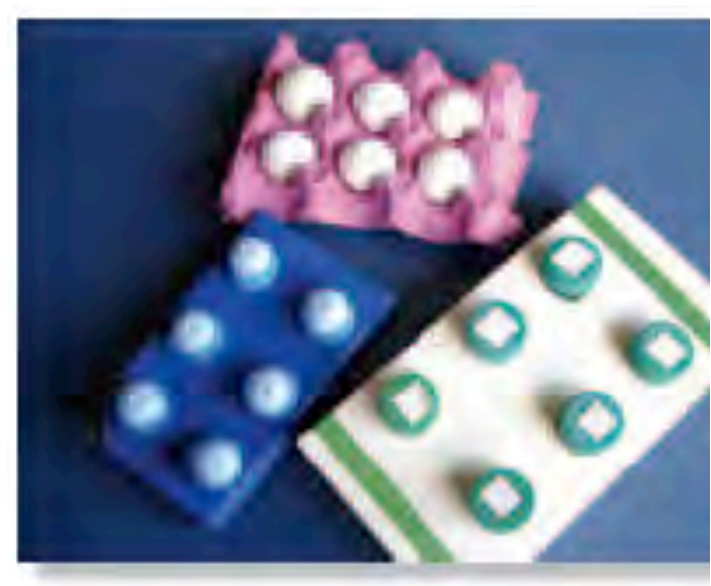

Figura 02: Cela braile (Recursos materiais)

Fonte: Sá; Campos e Silva (2007).

O trabalho com recursos materiais, além de promover a interação entre os alunos ajuda a concretização de conceitos por meio do cotidiano, utilizando os sentidos do corpo (tátil, cenestésico, auditivo, olfativo, gustativo e visual), se tornando indispensável para uma educação abrangente (BRASIL, 2001b).

Para ajudar no desenvolvimento do aluno com DV, especialmente o aluno cego, são necessários alguns materiais básicos, no processo ensino-aprendizagem, como mostra a figura 03.

Além dos recursos materiais, é de suma importância destacar os recursos tecnológicos como ferramentas essenciais para o processo de ensino-aprendizagem dos alunos com DV. Os recursos tecnológicos facilitam as atividades dos alunos e professores possibilitando o acesso à pesquisa e aos novos conhecimentos para os educandos (SÁ; CAMPOS; SILVA 2007). 


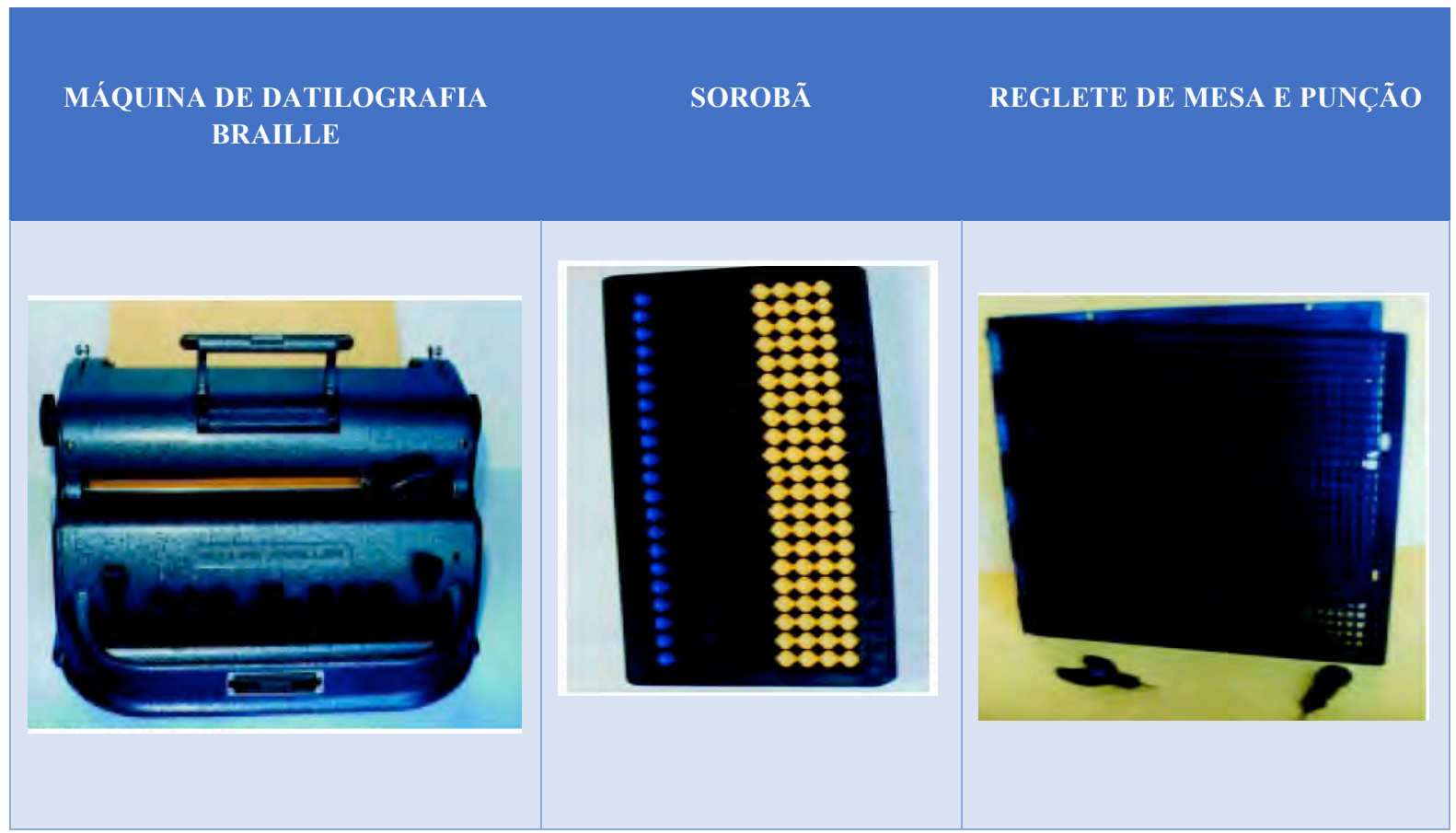

Figura 03: Materiais para o ensino do aluno com deficiência visual

Fonte: Brasil (2001b).

Os autores destacam entre os programas mais conhecidos no Brasil: dosvox, virtual vision e jaws, descritos no quadro 02. Esses programas podem ser utilizados pelos professores para facilitar o acesso dos alunos com deficiência à internet, a e-mails, processamento de textos e uma infinidade de aplicativos utilizados no computador. Desse modo, o aluno com DV se sente participativo no mundo atual em meio a tantas tecnologias.

Quadro 02: Programas voltados para o trabalho com o deficiente visual

Dosvox

Sistema operacional desenvolvido pelo Núcleo de Computação Eletrônica da Universidade Federal do Rio de Janeiro. Possui um conjunto de ferramentas e aplicativos próprios além de agenda, chat e jogos interativos. Pode ser obtido gratuitamente por meio de "download" a partir do site do projeto DOSVOX: http://intervox.nce.ufrj.br/dosvox 


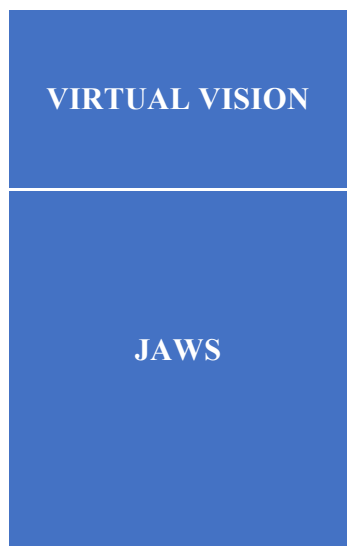

É um software brasileiro desenvolvido pela Micropower, em São Paulo, concebido para operar com os utilitários e as ferramentas do ambiente Windows. É distribuído gratuitamente pela Fundação Bradesco e Banco Real para usuários cegos. No mais, é comercializado. Mais informações no site da empresa: $\underline{\text { http://www.micropower.com.br }}$

Software desenvolvido nos Estados Unidos e mundialmente conhecido como o leitor de tela mais completo e avançado. Possui uma ampla gama de recursos e ferramentas com tradução para diversos idiomas, inclusive para o português. No Brasil, não há alternativa de subvenção ou distribuição gratuita do Jaws, que é o mais caro entre os leitores de tela existentes no momento. Outras informações sobre esse software estão disponíveis em: http://www.lerparaver.com

http://www.laramara.org.br

Fonte: Sá; Campos e Silva (2007).

Diante da importância e do potencial que programas como os referidos no quadro 02 apresentam para o desenvolvimento da aprendizagem de alunos com DV, é fundamental que estes estejam disponíveis nas escolas e nas salas de aula, ou seja, a utilização desses programas deve estar acessível aos alunos com DV, podendo ser elemento muito importante para a leitura, a escrita e a pesquisa desses estudantes.

Os programas podem possibilitar um maior acesso do aluno a informações e, dessa forma, facilitar a sua inserção na sociedade contemporânea. Entretanto, para que isso se torne uma realidade nas escolas, além da clara necessidade de adquirir os equipamentos e softwares necessários, isto é, ampliar a infraestrutura disponível nas escolas; também é fundamental que os docentes estejam capacitados, dispostos e interessados no uso dos programas.

Conforme Brasil (2001b) precisa ser criado nas escolas um ambiente rico de estímulos e novas experiências, promovendo situações novas de aprendizagem, com mudanças que devem fazer parte do cotidiano das crianças. Alunos com deficiência, mais especificamente com DV, precisam compartilhar seus conhecimentos assim como quaisquer outras crianças, mostrando para a sociedade que também são capazes de aprender e de se desenvolver.

Desse modo, para que os alunos com DV se sintam incluídos em contexto escolar é necessário que a escola e os educadores saibam respeitar as especificidades de cada educando possibilitando aos mesmos novas formas de conhecimento. 


\section{MÉTODO}

A metodologia utilizada neste estudo foi a pesquisa bibliográfica de caráter qualitativo, estando organizada a partir de levantamentos de obras a respeito da função da afetividade e das práticas pedagógicas no processo de inclusão do aluno com DV. Segundo Severino (2007, p. 122) a pesquisa bibliográfica pode ser conceituada da seguinte maneira:

[...] aquela que se realiza a partir do registro disponível, decorrente de pesquisas anteriores, em documentos impressos, como livros, artigos, teses etc. Utiliza-se de dados ou de categorias teóricas já trabalhados por outros pesquisadores e devidamente registrados.

A pesquisa bibliográfica oferece meios a partir de materiais já publicados, que auxiliam no desenvolvimento do estudo, permitindo explorar novas áreas e analisar sob um novo olhar diferentes temas relacionados à pesquisa, produzindo novas conclusões por meio de materiais estudados anteriormente.

Nesse sentido, foram utilizados livros, capítulos de livros, artigos de periódicos científicos e artigos publicados em anais de eventos científicos fundamentados em pesquisas consistentes e que tenham por objeto algum dos conceitos ou discussões que compõem a problemática deste trabalho.

O levantamento dessas obras se deu em bibliotecas públicas e privadas de Belém do Pará, como a do Campus I da Universidade do Estado do Pará, a biblioteca central da Universidade Federal do Pará e a biblioteca das Faculdades Integradas Ipiranga. Além disso, foram bastante utilizadas obras disponíveis na internet, especialmente, artigos de periódicos e de eventos acadêmicos.

A proximidade entre as obras utilizadas na pesquisa ocorre basicamente pelo objeto de estudo e por sua consistência teórica e/ou metodológica, pois, de fato, possuem naturezas bastante diversas, abarcando desde àquelas provenientes de esferas governamentais, perpassando por obras clássicas e chegando a obras mais recentes e menos conhecidas, porém de boa qualidade. 
Entendendo-se como pesquisa bibliográfica o levantamento de um material já publicado, com a finalidade de colocar o pesquisador em contato direto com tudo o que foi escrito sobre aquele determinado assunto (LAKATOS, 2011), essa pesquisa se caracteriza também como qualitativa, que de acordo com Minayo (2003, p.16-18), “[...] é o caminho do pensamento a ser seguido. Ocupa um lugar central na teoria e trata-se basicamente do conjunto de técnicas a serem adotadas para construir uma realidade". Este tipo de pesquisa trabalha com descrições, comparações e interpretações.

Nesse sentido, a pesquisa bibliográfica se baseia na coleta de um determinado material de diferentes autores e permite compreender uma gama de fatos de diversos pesquisadores. Essa investigação permite ampliar o conhecimento do assunto estudado.

\section{RESULTADOS E DISCUSSÃO}

A análise do referencial teórico desenvolvida anteriormente permite o desenvolvimento de algumas compreensões a respeito das discussões centrais apresentadas, relativas à inclusão do aluno com deficiência visual no contexto escolar e à função do afeto e das práticas pedagógicas.

A concepção de educação parte do princípio de que a escola é o lugar de todos (BRASIL, 2013). Onde os alunos devem se desenvolver e aprender de forma coletiva, sendo cada um atendido de acordo com as suas necessidades específicas. A Inclusão escolar deve promover aos alunos com DV melhores condições no ensino e também na estrutura física da escola com adaptações.

O trabalho com a inclusão necessita ser em conjunto, sendo realizado com todos os envolvidos nesse processo, ou seja, pais, alunos e toda a comunidade escolar, possibilitando o apoio às necessidades dos alunos, compartilhando e estimulando novos conhecimentos fazendo com que o aluno se sinta valorizado e amado no ambiente escolar (BRUNO, 2006).

O processo de socialização dos alunos com relação à escola precisa ocorrer de forma positiva, onde todos da equipe educacional estejam empenhados em desenvolver um trabalho afetuoso adaptando a escola às necessidades do aluno. A escola precisa propor ações 
significativas para os alunos. É muito importante deixar clara a função do professor no processo de ensino-aprendizagem de alunos com DV.

O professor vai organizar suas atividades com materiais necessários para que os alunos possam se desenvolver. Sendo assim, o educador deve propor atividades prazerosas e lúdicas, estimulando a interação das crianças com o meio escolar. Brasil (2001a) afirma que o professor necessita deixar o aluno experimentar várias situações de aprendizagem, para que possam compreender o ambiente ao qual pertencem.

Os alunos com DV são capazes de se desenvolver pessoalmente e intelectualmente, mas para que isso ocorra é necessário que seja oferecido a eles oportunidades de aprendizagem com novas metodologias e recursos didáticos adaptados a sua deficiência. Nesse contexto, o aluno passa a perceber e a sentir o meio em que se encontra inserido, ou seja, o ambiente escolar (BRASIL, 2001a).

Cabe aos professores o interesse e a dedicação em pesquisas para proporcionar aos alunos novas formas de receber os conhecimentos. Dedicação é a palavra certa para os profissionais da educação que buscam melhorias no ensino para alunos com DV. Usar a criatividade, confeccionar materiais adaptados, jogos, brinquedos e outros contribuirão muito para a aprendizagem do aluno. Brasil (2001 b) recomenda alguns critérios para a inclusão do aluno com DV em classe comum, como descritos no quadro 3:

Quadro 03: Critérios para a inclusão de alunos com deficiência visual em classes comuns

\begin{tabular}{|l|}
\hline A escola se estruture quanto aos recursos humanos, físicos e materiais; \\
\hline A inclusão aconteça desde a educação infantil; \\
\hline $\begin{array}{l}\text { A escola tenha conhecimento da sua forma de comunicação escrita e a orientação básica no relacionamento com as } \\
\text { pessoas deficientes visuais; }\end{array}$ \\
\hline A escola organize a classe comum de forma que possa reduzir o número de alunos da turma; \\
\hline Sua idade cronológica seja compatível com a média do grupo da classe comum que irá frequentar; \\
\hline A escola comum mantenha um trabalho sistemático. \\
\hline
\end{tabular}


Diante dos critérios apresentados anteriormente vale ressaltar a importância dos alunos com DV frequentarem a classe comum de ensino, pois têm os mesmos direitos que qualquer outro cidadão. O aluno com DV precisa conhecer e conviver no mundo das pessoas que enxergam, estando incluso não apenas na escola, mas também na sociedade.

Entretanto, é importante destacar a relação professor-aluno no contexto escolar, onde o docente deve conhecer o seu aluno e compreender as suas principais necessidades. Nesse momento, a função da afetividade tende a contribuir para que haja o desenvolvimento, a compreensão, a confiança, o respeito mútuo e a motivação dos alunos com DV.

Segundo Brasil (2001b), o professor pode facilitar sua educação por meio de algumas medidas perante o aluno com DV. Poderia se acrescentar a essas medidas a afetividade como elemento fundamental para a construção de um espaço repleto de carinho e respeito, onde o aluno passe a ser participativo e amado.

Entre as mediadas citadas por Brasil (2001b) vale destacar as seguintes: aceitar bem o aluno, não fazer discriminação; preparar os colegas para recebê-lo bem; relacionar-se bem com o aluno; dizer o nome do aluno deficiente visual sempre que desejar sua participação; identificar-se sempre que começar a conversar com o aluno deficiente visual; solicitar sua opinião na hora das conversas; fazer o aluno se sentir ativo e participante na hora das aulas (BRASIL, 2001 b, p.100).

Diante dessas medidas, a afetividade passa a fazer parte da rotina escolar e o professor a utilizar estratégias pedagógicas dinâmicas e criativas, demonstrando prazer em ensinar, em ministrar aulas, estimulando e contribuindo para o processo de ensino-aprendizagem desses alunos.

A escola como um todo é um espaço onde acontecem as interações sociais favorecendo a troca de experiências e opiniões. Contudo, é importante direcionar o olhar à prática pedagógica do professor, e estar atento ao desenvolvimento dos alunos com deficiência visual, pois cabe ao professor oferecer métodos diferenciados a esses alunos. " $\mathrm{O}$ método é, em linhas gerais, um conjunto de técnicas de ensino, cuidadosamente organizadas com um fim específico" (FREITAS, 2009, p. 15).

Freitas (2009) afirma que a sala de aula deve ser o lugar com o qual os alunos se identifiquem, circulem livremente e tenham acesso aos materiais e informações. Nessa 
perspectiva, o professor deve ser o principal responsável pela construção desse espaço educativo, favorecendo a elaboração de saberes para os alunos com DV.

Para Fernández (2001) o processo de ensino-aprendizagem envolve vínculos entre quem ensina e quem aprende. Portanto, existe uma relação de troca entre ambas as partes, ou seja, entre professor e aluno. O professor deve mediar as relações afetivas dentro da sala de aula, fazendo com que as crianças vivenciem o afeto em seu cotidiano escolar.

Construir boas relações no ambiente escolar facilita o processo de construção do conhecimento e, consequentemente, da aprendizagem de alunos com DV na escola, o que faz do afeto uma ferramenta imprescindível para a prática pedagógica do professor que busca incluir o aluno com DV no contexto educacional.

\section{CONCLUSÃO}

O estudo das obras levantadas permitiu inferir que a inclusão dos alunos com DV na escola possui importância fundamental, sendo um fator determinante para o desenvolvimento desse aluno enquanto sujeito do processo-ensino aprendizagem. A educação inclusiva implica na participação de todos os agentes do contexto escolar, reconhecendo e respeitando as diferenças individuais de cada aluno.

Contudo, se o compromisso é com o desenvolvimento do aluno cabe à escola e ao educador se voltar à formação não apenas de um futuro trabalhador, mas de um cidadão capaz de lidar com os desafios e dificuldades impostos pelo mundo atual, munido das ferramentas necessárias para o seu avanço. Ferramentas essas capazes de realizar um trabalho mais afetuoso com metodologias diferenciadas de acordo com a necessidade do aluno.

Isso porque somente partindo da relação afetiva no ambiente escolar e das práticas pedagógicas inovadoras desenvolvidas pelo professor, o aluno com DV consegue construir bons vínculos no contexto educacional, estando aberto para receber novos conhecimentos se sentindo valorizado e, acima de tudo, incluso no processo educacional. (CODO e GAZZOTTI, 1999).

Portanto, essas reflexões citadas nos mostram que a inclusão do aluno com DV no contexto educacional deve se realizar em sua plenitude, não sendo apenas uma mera inserção 
do aluno a escola, mas sim a sua efetiva integração no âmbito educacional de forma mais afetuosa e participativa. Pois a inclusão escolar do aluno com DV merece um olhar mais cuidadoso e atencioso.

Por fim, para que a inclusão de alunos com DV seja realmente efetivada faz-se necessário que as escolas sejam democráticas para atender as necessidades específicas de seus alunos, sendo assim, a educação ganha uma nova organização passando a incluir os alunos com DV. Portanto, propôs-se neste estudo iniciar uma reflexão em nível teórico acerca das dificuldades encontradas pelos alunos com DV no contexto escolar.

Entretanto, uma compreensão mais detalha dessa problemática envolveria a necessidade de desenvolver pesquisas empíricas voltadas para avaliar as seguintes questões: Que medidas as secretarias estaduais e municipais de educação vem desenvolvendo para incluir o aluno com deficiência visual na escola? Como as escolas lidam com o aluno com DV? A afetividade realmente marca as relações no contexto escolar? Qual a preparação técnica e pedagógica que os professores recebem para lidar com o aluno com DV?

Estes questionamentos podem funcionar como importantes questões norteadoras de pesquisas futuras que tenham como propósito último contribuir para a compreensão da complexa tarefa de inclusão de alunos com deficiência visual no ensino regular.

\section{REFERÊNCIAS}

ALMEIDA, Ana Rita Silva. A afetividade no desenvolvimento da criança. Contribuições de Henri Wallon. Inter-ação, Revista Fac. ed. UFG, 33(2), 2008.

AMORIM, Márcia Camila Souza de. Afetividade na educação infantil. In: Interdisciplinar: Revista

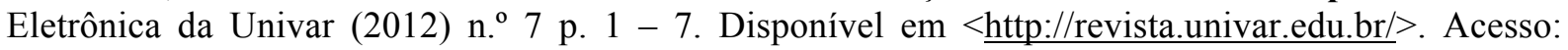
21/11/2013.

ANDERSEN, Roberto. Afetividade na educação: psicopedagogia. 2 d. São Paulo: Allprint editora, 2011.

BRASIL. Lei n ${ }^{\circ}$ 9.394, de 20 de dezembro de 1996. Lei de Diretrizes e Bases da Educação Nacional.

Diário Oficial da União, Brasília, DF, 24 dez. 1996. Disponível em URL:

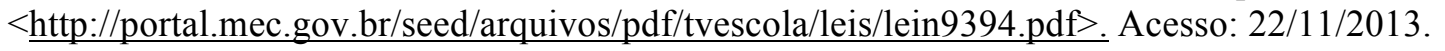




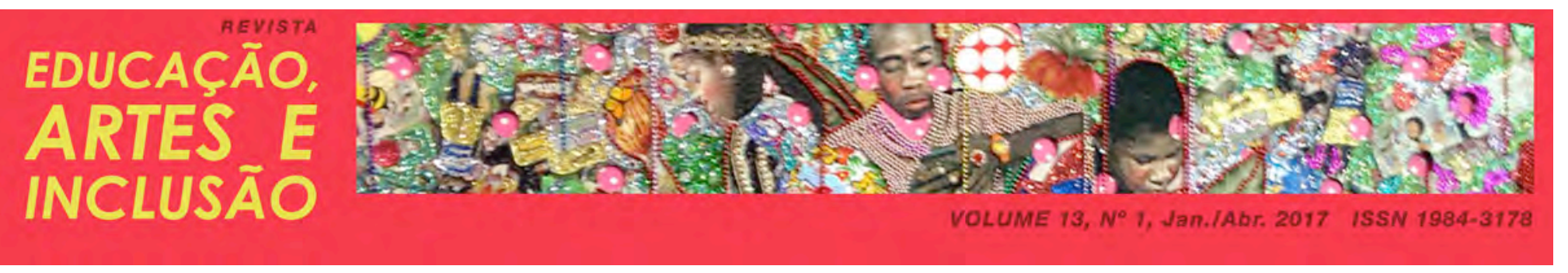

Programa de Capacitação de Recursos Humanos do Ensino Fundamental: deficiência visual. Vol 1. Brasília: Ministério da Educação, Secretaria de Educação Especial, 2001a.

Programa de Capacitação de Recursos Humanos do Ensino Fundamental: deficiência visual. Vol 2. Brasília: Ministério da Educação, Secretaria de Educação Especial, 2001 b.

DECRETO N 5.296 de 02 de dezembro de 2004. Diário Oficial da União, Brasília, 03 de dezembro de 2004.

\section{Disponível em: $<$ http://www.senado.gov.br/legislacao/const/con1988/CON1988_05.10.1988/CON1988.pdf $>$.Acesso: 02/04/2017.}

BOATO, Elvio Marcos. Henri Wallon e a deficiência múltipla: uma proposta de intervenção metodológica. São Paulo: Loyola, 2009.

BRUNO, Marilda Moraes Garcia. Educação infantil: saberes e práticas da inclusão. 4 ed. Brasília: MEC, Secretaria de Educação Especial, 2006.

CARMO, Maria Carolina do. O papel dos afetos no processo de formação dos psicólogos. Campinas: PUC, 2011.

CODO, Wanderley; GAZZOTTI, Andréa Alessandra. Trabalho e afetividade. In: CODO, Wanderley (Coord.). Educação: carinho e trabalho: Burnout, a síndrome da desistência do educador, que pode levar à falência da Educação. Petrópolis (RJ): Vozes, 1999.

DEMO, Pedro. Aprendizagem no Brasil: ainda muito por fazer. Porto Alegre: Mediação, 2004.

FERNÁNDEZ, Alícia. O saber em jogo: a psicopedagogia possibilitando autorias de pensamento. Porto Alegre: Editora ARTMED, 2001.

FERREIRA, Aurélio Buarque de Holanda. Miniaurélio Século XXI: o minidicionário da língua Portuguesa. 4 ed. Rio de Janeiro: Nova Fronteira, 2001.

FREIRE, I. M. Um olhar sobre a diferença: Interações e experiências dos adultos com a criança nãovisual. In: BIANCHETTI, L., FREIRE, I. M. Um olhar sobre a diferença. Interação, trabalho e cidadania. 3. ed. Campinas: Papirus, SP, 2000.

FREIRE, Paulo. Pedagogia da autonomia: saberes necessários à prática educativa. São Paulo: Paz e terra, 2001.

FREITAS, Olga. Equipamentos e materiais didáticos. Brasília: Universidade de Brasília, 2009.

GADOTTI, Moacir. Concepção dialética da educação: um estudo introdutório. 12 ed. São Paulo: Cortez, 2001.

INSTITUTO NACIONAL DE ESTUDOS E PESQUISAS EDUCACIONAIS - INEP. Censo escolar 2015: notas estatísticas. Brasília: INEP/MEC, 2016.

LIBÂNEO, José Carlos. Pedagogia e pedagogos, para quê? 12 ed. São Paulo: Cortez, 2010. 
MAHONEY, Abigail Alvarenga. A constituição da pessoa: desenvolvimento e aprendizagem. In: MAHONEY, Abigail Alvarenga e ALMEIDA, Laurinda Ramalho de (Orgs.). A constituição da pessoa na proposta de Henri Wallon. São Paulo: Loyola, 2004.

MARCONI, Marina de Andrade; LAKATOS, Eva Maria. Metodologia do trabalho científico. 7 ed. São Paulo: Atlas, 2011.

MINAYO, Maria Cecília de S. Pesquisa social: teoria, método e criatividade. 22 ed. Rio de Janeiro: Vozes, 2003.

MINETTO, Maria de Fátima. Currículo na educação inclusiva: entendendo esse desafio. - 2 ed. Curitiba: Ibpex, 2008.

MANTOAN. Maria Teresa Eglér. O direito de ser, sendo diferente, na escola. In: III Seminário Internacional Sociedade Inclusiva Ações Inclusivas de Sucesso, 2004, Belo Horizonte. Anais... Belo Horizonte: PUC Minas, 2004.

RODRIGUES, S. A. Expressividade e emoções na primeira infância: um estudo sobre a interação criança- criança na perspectiva walloniana. Dissertação (Mestrado em Educação). Universidade Estadual Paulista, Presidente Prudente, 2008.

SÀ, Elizabet Dias de; CAMPOS, Izilda Maria de; SILVA, Myriam Beatriz Campolina. Atendimento educacional especializado: deficiência visual. SEESP / SEED / MEC Brasília/DF - 2007.

SADALLA, Ana Maria Falcão de Aragão; AZZI, Roberta Gurgel. Contribuições da afetividade para a educação. In: VALLE, Luiza Elena Leite Ribeiro do (Org.) Neuropsicológica e Aprendizagem. São Paulo: Robe Editorial. 2004.

SANTOS, Júlio César Furtado dos. O desafio de promover a aprendizagem significativa. Revista UNIABEU, v. 20, p. 29-37, 2006.

SEVERINO, Antônio Joaquim. Metodologia do trabalho científico. 23 ed. São Paulo: Cortez 2007.

WALLON, Henri. A evolução psicológica da criança. 2 ed. Lisboa: Edições 70, 1995. 